Article

\title{
Heritage Value through Regeneration Strategy in Mapo Cultural Oil Depot, Seoul
}

\author{
Jiae Han ${ }^{1, *}$ and Soomi Kim ${ }^{2, *(1)}$ \\ 1 Major in Architecture, Department of Architectural Engineering, Hongik University, Sejong 30016, Korea \\ 2 School of Architecture, Soongsil University, Seoul 156743, Korea \\ * Correspondence: jiaehan@gmail.com (J.H.); soomikim@ssu.ac.kr (S.K.); Tel.: +82-44-860-2021 (J.H.); \\ +82-2-820-0991 (S.K.)
}

Received: 5 July 2018; Accepted: 29 August 2018; Published: 18 September 2018

\begin{abstract}
Regeneration projects are a crucial tool in helping cities improve their heritage value. This includes the rehabilitation of industrial facilities, a practical solution to increasing urban sustainability. Seoul's Mapo Cultural Depot, launched in 2017 after and international competition in 2014, is a representative model of such industrial heritages. This winning design focused on rehabilitating the site throughout both the design and construction periods, valuing preservation over new construction even at the initial stages of the competition. In this study, we examine the Mapo Cultural Depot in terms of its balance with the natural surroundings, architectural tectonics, and emotional remnants. We argue that its physical appearance, landscaping, and tectonic relation, composed of a specific spectrum of time accumulation, help people experience a sense of collective memory. In this way, a sense of time and place are embedded in materiality and important to consider when moving toward urban sustainability. Our findings have implications for a new perspective on concrete regeneration strategies.
\end{abstract}

Keywords: heritage value; regeneration strategy; urban sustainability; Mapo Cultural Oil Depot; natural surroundings; architectural tectonics; emotional remnants

\section{Introduction}

\subsection{Historical Background}

Modern cities are focusing on revitalizing their cultural heritage both in architecture and other fields. Renovating urban industrial heritage buildings is an important part of this process, one that cities have long been engaging in as urbanization continues to increase. This has become even more pressing as in recent years, urban problems have threatened people's quality of life and changed the nature of community, thereby increasing the need for sustainable urban development. In this context, sustainability includes not just development-related practices, but also an increase in well-being and social bonds, community building, social support, and urban infrastructure renewal [1]. Restoring long-standing industrial remnants can be a way to both enhance urban sustainability and reinforce a city's heritage, thereby putting sustainable design into a city's vernacular. Buildings like the Tate Modern maximize cultural heritage while redeveloping historical industrial property. Similarly, the Wapping Hydraulic Power Station, built in 1890, provided power to central London for 100 years. However, according to the trend of the times, its usefulness ran out, and was closed in 1977. Since then it was left to pollute the area. That was, until art director Jules Wright discovered the cultural value of this place and transformed it into a sensuous space. The Wapping Project, which merged with the surrounding historical sites while preserving the old 19th century facade, revitalized the area by 
rebuilding it as a cultural complex space in 2000 [2]. In such a way, urban design is one of the most important tools for creating a sustainable society.

However, urban design cannot be approached with a universal methodology. Instead, designers and city planners must consider a region's unique culture and characteristics. One example of such industrial revitalization done with an area's unique identity in mind is the Mapo Cultural Depot in Seoul. The building shows evidence of a variety of historical identities, and the land on which it sits has transitioned from a naturally hilly area on the Mt. Maebong Ridge, to a petroleum reservoir, to vacant land, and finally to the cultural park that is its present day incarnation.

The logic that approached this Mapo Depot (Figure 1) as a research subject is as follows. This is also a factor that strengthens the heritage value and unique identity of the facility. (1) The site is accumulated by laminating several time zones, and (2) the facilities that reveal each time zone are preserved under the protection and policy of the government. (3) It is a project that clarifies the big direction of regeneration by linking this with the current time zone as the main design strategy.

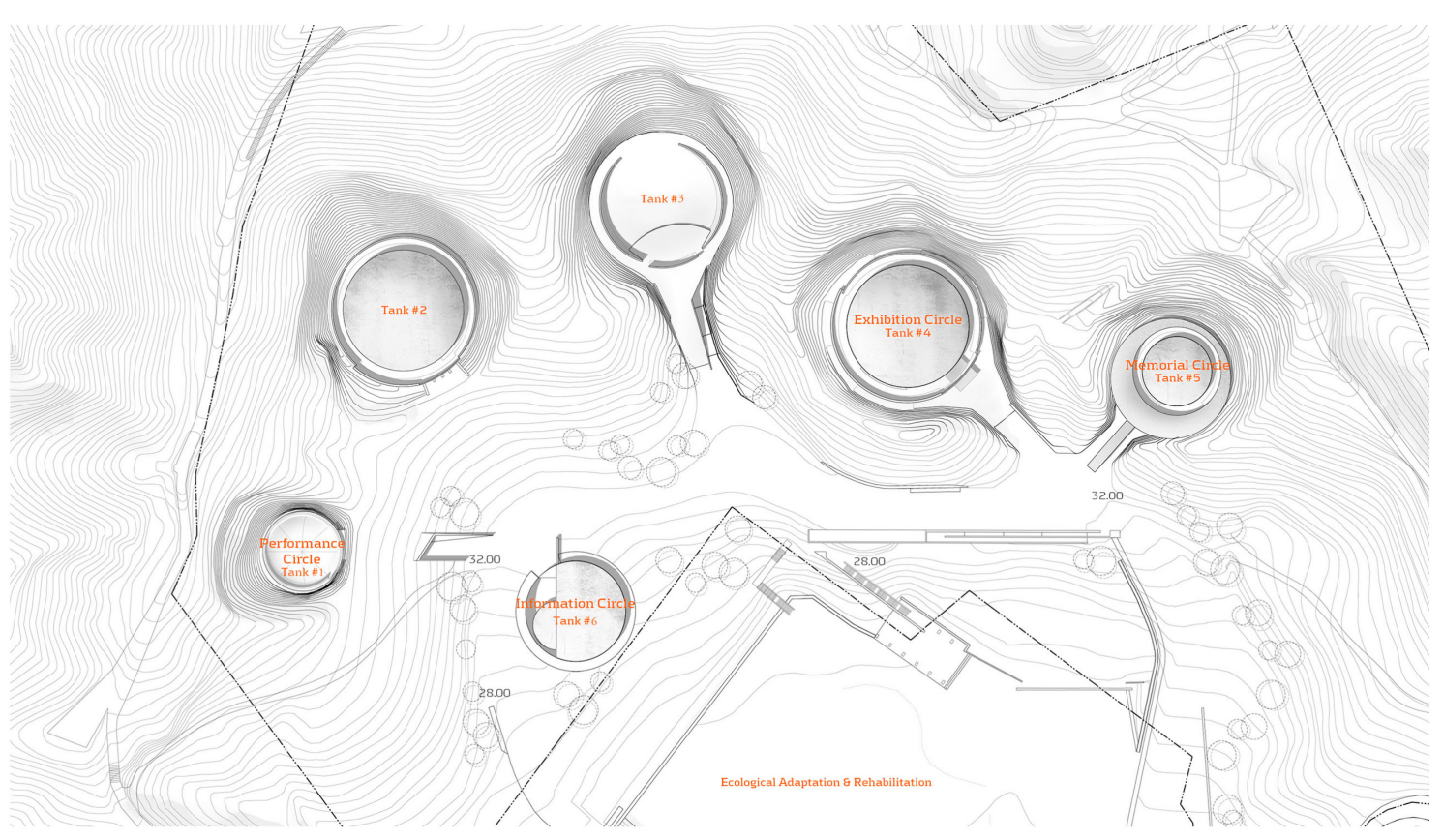

Figure 1. Original layout of the Mapo Oil Depot, Seoul (Credit: RoA Architects).

In the 1970s, two oil shocks in Korea meant that most refineries only had about 30 days' worth of oil. The government, therefore, decided to build a national oil depot to solve this problem. In 1976, and at the foot of Mt. Maebong in Seongsan-dong, Mapo-gu was excavated and five oil storage tanks were buried, reserving 1.31 million barrels [1]. This land was a logical choice for the depot: Mt. Maebong was a rocky mountain that could protect the five tanks (which contained volatiles, diesel, and bunker fuel) within its bedrock. Two years later, in 1978, the oil depot was joined by landfills in Nanjido, about 500 m away.

Then, before the 2002 World Cup games, Nanjido (which was in the area surrounding the World Cup Stadium) was turned into a World Cup Park. The oil reserve base $500 \mathrm{~m}$ away was relocated, due to landscaping and safety problems. In November 2000, the reserves were moved to the Yong-in Oil Depot; the base closed and some of its sites were used as temporary parking for the World Cup Stadium.

Since then, however, Seoul has attempted to revitalize the city's idle land and industrial cities while maintaining places' meaning, value, and potential. The city, therefore, began the process of revitalizing the Mapo Oil Stockpile site in a way that would meets the core values of the new era, including sustainability. As part of this effort, in 2013 it launched an idea contest, where citizens and 
experts could suggest ways to use the land through discussions and public hearings. The citizen contest received a total of 267 submissions, and an additional international contest for students and professionals resulted in an additional 299 submissions (105 of which came from 35 countries other than Korea). These basic ideas were then reinterpreted by experts. The final plans were developed together with citizens' consensus and public opinion and conducted with the motto, "Design for Citizens" [3].

Today, the depot reflects this process of conceptual and practical change. The winner of the contest was an entry titled "Time Read from the Land," which focuses on the distinctive idea of architectural archeology. The plans trace the process of time through the site's design and propose a new perspective to preserving heritage value as Figure 1 above. These guidelines were adopted and promoted as much as possible in the depot's renovation process. In this way, the revitalization of the Mapo Cultural Oil Depot focused on a unique vernacular approach that embraced the process of city growth and change over time and incorporated citizen feedback and opinions.

\subsection{Methodology for Critical Approach to Heritage Value}

There are several viewpoints dealing with contemporary trends in urban design. Some are focusing on philosophical aspects. Others are emphasizing on the scientific contribution of the authors. Frequently, those are mixed together. Based on this, the methods how to make a critical approach can be classified. Followings are representative methodologies.

In an international context, the theories and ideals dominating today's urban design discourse have been examined and defined in various ways, resulting in differing categorizations and definitions such as "territories of urban design," "images of perfection," "urban design force fields," "integrated paradigms in urbanism," "urbanist cultures and approaches to city-making," "new directions in planning theory," "models of good design," and "typologies of urban design" [4]. Among these methodologies, this study follows the new directions in planning theory method. The theoretical content is the value of sustainability and the new direction is to find the value of heritage. This regeneration has value as a critical approach.

The majority of industrial facilities that have stopped operating due to changes in the industrial structure are exposed to the inevitable fate which is disposal. It is not easy to continue to function usefully despite changes in society. In most cases, when the usefulness comes to an end, it disappears. Industrial facilities that were obsolete and discarded were recognized as causing environmental pollution and damaging the landscape. However, these are places that withhold history, and the changes in the paradigm that the architectural philosophy, technology, design and artistic sense are integrated and perceived as an industrial heritage with cultural value has begun to appear in modern society [2].

This paper analyzes how this design competition and the final incarnation of the Mapo Oil Depot allowed designers and planners to uncover corporate memories and meanings regarding the land. In addition, we examine various physical features, exploring in detail how they lead to a better understanding of the intent and characteristics of industrial heritage and urban sustainability (Figure 2). To this end, Section 2 provides a literature review of relevant studies regarding heritage value and the Mapo Cultural Oil Depot. This section also defines the terms "value of reuse" and "heritage value" and provides additional historical context. Section 3 analyzes the architectural heritage of each tank. Finally, Section 4 presents the findings of our analysis, arguing that the Oil Depot's regeneration strategy considers three unique perspectives: (1) Awareness of the natural surroundings, (2) tectonic artifice, and (3) incorporation of emotional remnants. That is, as a discussion section, Section 4 shows the logical structure of the approach as shown in Figure 2 above. This is a discussion covering the entire site, starting with Section 4.1, which analyzes techniques for dealing with ground, and leading to Section 4.2, which is an internal discussion of each tank. Section 4.2 will be an active discussion of the actual activities and interactions that take place on the walls and floors of the tank within a given site. This is a different view from the ground discussion started in Section 4.1, with a smaller scale and a more detailed analysis range. Section 4.3 attempts to approach another hierarchy. These analyses connect to the step of deriving result. This focuses on the process by which memory and perception are mobilized 
in psychological processes that accept old structures and new materials for its level of evaluation and contribution. Based on the discussion in Section 4, the overall evaluation is based on the difference between the original design intention and the implementation in Section 5.1. In Section 5.2, we show the implications of this study in the pursuit of the value of the heritage and suggest the direction of the design strategy that should be considered in the recycling of architectural industrial heritage.

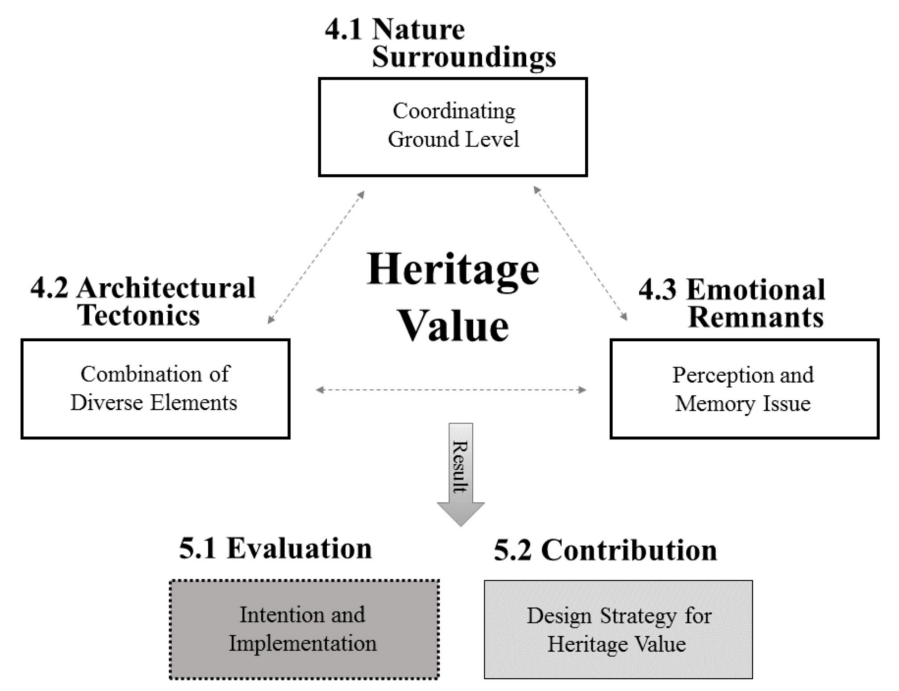

Figure 2. Outline of Mapo Oil Depot's revitalization strategy (Credit: Authors).

\section{Mapo Oil Depot's Heritage Value}

\subsection{Value of Regeneration toward Urban Sustainability}

Pursuing urban reuse, rather than adding new value, will ultimately ensure urban sustainability. To this end, various international scholars have examined and defined several terms in urban design. The three dominant ideals are New Urbanism, post-urbanism, and sustainable urbanism—although other categories, such as everyday urbanism, ecological urbanism, and landscape urbanism, are also common. All these approaches share a concern with shaping and composing public spaces and creating livable and healthy places that include variation, interest, familiarity, interaction, and contrast [4].

In an attempt to supplement existing definitions of the city as entity, some environmental researchers have adopted the term "urban ecosystem" to identify the qualities of urban areas (Douglas 1981; Millennium Ecosystem Assessment 2005; Sterns and Montag 1974) [5]. Through this lens, urban sustainable development can be understood in terms of economic, environmental, and social factors. Indeed, in 2002 the WSSD (World Summit on Sustainable Development) adopted the Johannesburg Declaration, which stated that sustainable development involved the balanced development of environment, society, and the economy. According to this model and the Sustainable Communities Plan, sustainable communities are places where people want to live and work, now and in the future. They meet the diverse needs of existing and future residents, are sensitive to their environment, and contribute to a high quality of life. They are safe and inclusive; well planned, built, and run; and offer equality of opportunity and good services for all [6].

In environmental terms, sustainable development focuses on protecting the integrity of ecological systems. It is realized through efforts to improve quality of life, preserve ecological diversity, and reproduce resources while minimizing waste [7]. It considers the long-term impacts of urban development on the environment and efficiently utilizes existing natural resources. In addition, environmental sustainability recognizes the value of ecosystems as the sole source of air, water, and soil. It includes the restoration and maintenance of the natural environment through the utilization of natural resources and reuse resources, such as greening and water circulation systems [6].

Social sustainable development seeks to enrich the human dimension by harmonizing social relations and cultural pluralism. Such a viewpoint views culture as the glue binding together all other 
concerns and underlying political and economic behavior. In addition, culture can build values that drive collective action toward a global sustainable future. Social sustainability deals with maintaining human's quality of life and harmony through socio-cultural diversity and maintaining a harmonious relationship between development and value norms. It is related to local culture, identity, accessibility, stability, and equity, ultimately aiming to revitalize local communities [7]. In addition, it makes efforts to promote community through residents' voluntary participation in the urban development process and in the ability to adapt to changing community needs and desires [6].

Finally, economic sustainable development aims at improving human welfare through increased consumption and the production of goods and services. Economic sustainability is focused on citizens' welfare and the supply, consumption, and production of goods. This starts with the recognition that environmental resources are limited, and must be preserved to meet the needs of present and future generations. It balances economic benefits with the potential future costs. On the quantitative side, economic sustainability prioritizes efficient growth, development, and productivity [8]. In terms of quality, it coordinates the utilization of resources and direction of technological development. As city and local economies continue to steadily develop, many governments are instituting specific economically sustainable initiatives such as energy conservation, new material development, material recycling, and construction methods that consider logistical costs and energy-saving transportation systems [6].

All three of these perspectives towards urban sustainability can be seen in the Mapo Oil Depot's renovation [9]. Firstly, environmental sustainability: The depot's primary feature is its maintenance of the local ecosystem and morphological harmonization with the surrounding environment. From above, the Depot looks like a human hand: The cultural courtyard is the palm and the remaining five tanks are the ends of the fingertips. The different elements are made with bedrock and preexisting natural elements. In addition, the designers efficiently utilized existing natural resources to preserve the original form of the space. The tanks are made of gray exposed concrete and exposed ceilings, similar to their original form, while also blending harmoniously with surrounding rock walls and forests. The moss, retaining walls, oil pipelines, and pillars inside the facility all convey the space's history. Finally, the designers have made obvious efforts to conserve local ecosystems.

In terms of social sustainability, the revitalized Depot was developed explicitly to foster identity regeneration and citizen participation. The area's oil and construction era of the 1970s is preserved, recognizing the Depot's history and culture, and today the space has been reborn as a gathering place for local citizens. The tanks were renovated with the competition results in mind [9]. Many citizens, students, and experts proposed renovating the tanks into cultural, educational, experience, and leisure facilities that could host exhibits, performances, and other events. The designers also considered accessibility when renovating the space. The Depot was designed as a secure facility and was originally located underground, inaccessible to local citizens. However, today the Depot is a fully open space, both physically and psychologically. The fact that the site was constructed through citizen feedback gave them a sense of greater psychological comfort as well. Finally, this space plays a role in community revitalization, taking part in the city's functions through an independent cooperative economic system [9].

Finally, the Depot was also designed with economic sustainability in mind. First, it is noteworthy that all elements are made from recycled resources. The Depot also prioritizes energy conservation: All heating and cooling facilities are $100 \%$ renewable and use geothermal energy. The Depot hosts a future-oriented local economy that fosters not only cultural consumption, but also production.

\subsection{Historical Remnants of an Architectural Heritage}

The tendency to build new buildings on historical sites is not new. Bernard Tschumi's New Acropolis museum, for example, both reflects the ancient Greek archaeological site on which it is built and its identity as a thoroughly new museum (Figure 3a). As visitors move from the ground floor archeological site to the top floor, which offers a 360 degree view of the Acropolis and the rest of Athens, they receive a strong message about the relationship between the past and the present. Likewise, Peter Zumthor's Kolumba 
Museum in Cologne, Germany (Figure 3b) was built on the ruins of a late-Gothic cathedral destroyed during World War II [10]. New gray brick and columns expand the relationship between the old cathedral and the new exhibition space, thus harmonizing the past and present.

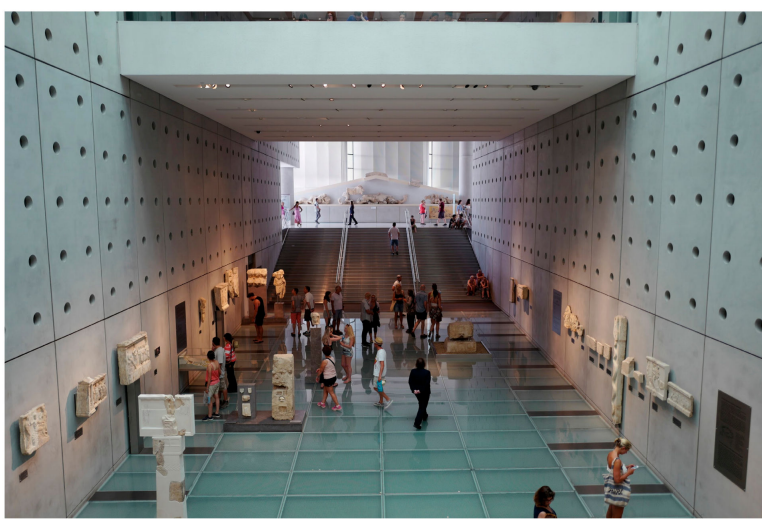

(a)

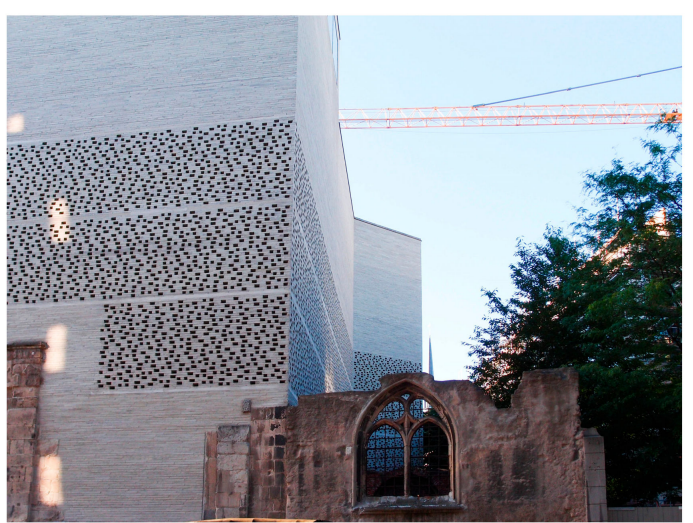

(b)

Figure 3. (a) Bernard Tschumi, New Acropolis Museum [11]; (b) Peter Zumthor, Kolumba Museum [12].

The process of designing new architecture on top of existing historical structures is a complex process in which structural stability, visual beauty, and ease of use must be balanced together. Architects and designers must also determine how to maintain the existing structures to bring together past eras with the present; this will have a large impact on the new space. In the case of the Mapo Oil Depot, which is several facilities rather than a single structure, designers chose to highlight the relationship between the various structures and harmonize them with the design of the upper level.

\subsection{Mapo Oil Cultural Depot as a Heritage Site}

In 2013, when the redevelopment contest was developed by Seoul Research Institute as part of its master plan to utilize the Mapo Oil Depot, the site was mostly unknown. The oil reserves base was left over from the past industrial era and had lost its use. Instead, the redevelopers wanted to build an "open park," a new site that would provide citizens with facilities for performing, exhibiting, information exchange, and relaxation. They saw building a new cultural depot as the most important part of the plan to change the site from a place to store oil to a place to store Seoul citizens' cultural values. In light of this, the development team dictated a vision for the redevelopment: To make the Depot a "civic place and complex cultural space centered around the environment and recycling" while including spaces for "performance and lecture, exhibition and experience, and information exchange." To this end, a variety of usages for the site were proposed, including a digital media center, environmental exhibition education center, video culture complex, etc.

In August 2014, the international design competition solicited ideas based on this stated vision. As well as proposing a vision for the space, entrants were instructed "to make the most of the place's industrial heritage, including five huge buried oil tanks and their unique spatial characteristics" [1]. The instructions continued, "the goal of the design is to create parks that can provide diverse cultural activities for citizens by utilizing existing reserves and oil storage tanks located within the site that were used as oil reserves in the past."

A total of 227 architects from 16 countries participated in the competition. The judges ranked the entries as follows:

The most important thing that judges had in mind during the review process was how participating architects paid attention to the existing situation, including the oil tanks, when developing their design. This attention to the situation does not just mean preserving the site's present condition. It means developing through architecture dynamic thoughts between past history, present condition, and future regeneration. The judges emphasized that the present design is a virtue to possess-minimizing architectural physical 
intervention but ensuring future possibilities. In addition, the judges discussed not only how to design buildings using the oil tanks, but also how to create a place that included an understanding of the overall environment, and considered the possibilities in steel structures and concrete tanks. In expression, entries did not have to include a vivid image of the designed space; it is possible to enumerate ideas through drawings that faithfully include thought, logic, old law, and technique [3].

The winning project was titled "The Time We Read from the Land," by Seogu Hoe and RoA Architects. It was said that this project received strong support from Japanese architect Ito Toyo, who was a judge. Architect Jo Sung-ryong, who served as a judge on a storytelling series that reproduced the process of building the cultural depot described the winning entry by saying, "the construction was a process of excavation."

Hoe's idea of "time read from the ground" was simple: "Let us look at the construction process at the time of the construction and trace the remnants on the ground." The judges described the entry as "the only work in which tanks and landscapes unite," lauding it its refrain from excessive design and maximization of the land's unique potential. The plan could be called an "archeology of architecture," a fitting solution for this project: Hoe imagined the process of renovating the oil tanks as if they were artifacts to be excavated. His contest entry described how to work in reverse order to find traces of the intervention, revealing them and building up the space. The original work restored the work road used while building the oil depot and used it as an access road, connecting different eras in time and space with in-depth design research, a powerful narrative, and visual rhetoric.

"RoA's director, Kim Kyung-do, described the rationale behind the project:

Even if it was closed and covered with soil, the idea of the previous blasting trail was left on the rock. It would have started construction with a small ramp, leading to the boulder-filled mountain side. I followed the ramp, blasted it out, made a big pit, built a tank, built a concrete retaining wall around the tank, covered it with earth, and came back out of the ramp. If in the past, it was a process of burying the tank along the ramp, the revitalization process could be seen as a process of following in and opening the tank [13]."

In other words, Hoe and RoA's main goal in the design was a continuing structure that permeated past and present and included the memory of the land. Such a design is closely linked to heritage values, cultural identity, and the aesthetic appreciation of natural and cultivated landscapes, key elements of urban sustainability.

\subsection{Alternative Proposals toward Heritage Value}

Discussion of the winning proposal becomes even richer when consider the other entries at the same time. Other proposals also focused on preserving the Depot's heritage value, common social and environmental values, and a three-dimensional system. "The Park T6" won the second prize (Figure $4 \mathrm{a}, \mathrm{b}$ ). This proposal punched through the steel walls of the existing tanks to create patterns of light. It also included as a partial modification of the tanks' roofs or floors so that it could be used as a stage and seat an audience. In this way, the space required between the tank and the concrete retaining wall and that inside the tank was maximized for programming purposes. Because of that, it has become a limitation to sustain "other possibility" of space, the value of empty space.

The work that took third place captivated the judges with its restrained beauty. Instead of creating new structures, slabs, and walls in the circular oil tanks, the architect proposed seeing the tanks as vessels that had that contained a liquid and suggest a process of pouring liquid concrete through the tanks to create new forms. The displacement of fluids into solids and the hardening of concrete understood people's movement within the space in a totally different way. While the resulting appearance of each tank may differ greatly from its previous stat, the contrast is clear to users. However, the judges determined that the process would overpower the way in which the space was created and counteract the potential of the empty tanks. 
Nine other works won honorary mentions. These proposals all took various perspectives toward towards creating a new space. One placed installations outside the tanks, and highlighted the beauty of light shining into the tanks' empty space. Another reinforced the tanks, one stressed the tanks as a historic relic, and another suggested ecological uses and structures for the tanks.

While all these other entries included important viewpoints, the winning proposal was clear. After three deliberations consisting of debates and votes, the first proposal was unanimously decided upon. After that, debates among the judges decided the second and third place winners. In other words, the judges chose a winning entry with great confidence which approve that strength of final winner was clear enough.

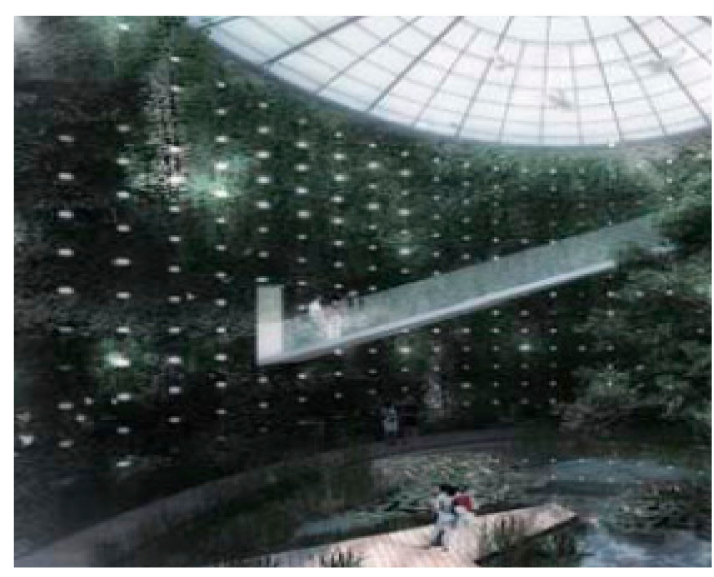

(a)

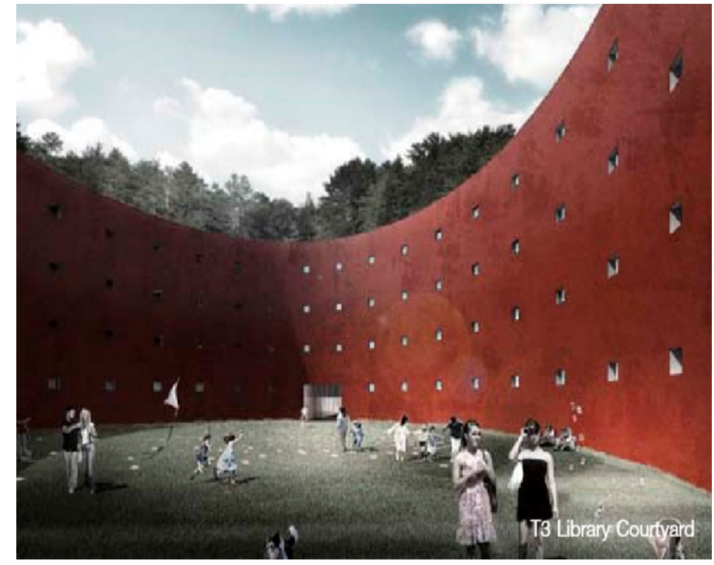

(b)

Figure 4. Second Prize winner, "The Park T6" among alternate proposals from the International Design Competition. (a) T1 Wetland Garden, (b) T3 Library Courtyard (Credit: Arcbody Architects Co., Ltd. + Open Plus).

\section{Oil Tanks' Architectural Heritage}

The heritage of the Depot is clear when viewing the structure. It is a vertical body built on the ground, and the rock funnel from Mt. Maebong, the concrete wall, and the inner oil tank are the main objects preserved from the original structure. The Depot's physical structure, therefore, is interpreted based on the relationship of various vertical bodies placed on the ground. A balanced approach involves seeing the relationship between the land and the manmade structures organically, and highlighting the continuous linkage between Depot's original function as an oil reserve and the surrounding landscape. The contour line (A) shows the oldest identity of the site, revealing the natural hilly line of Mt. Maebong before the oil storage base was created. This enclosure encompasses all the tanks with the exception of Tank 6, which is newly created, giving each a different degree of exposure and concentration. Second, the concrete wall (B) inside the contour line is a vertical wall built for protecting the original oil tank. It is a rigid structure built along the surrounding natural landscape. Due to its original purpose, it does not lead to greater accessibility or visual penetration but is merely meant to convey solidity and weight. Third is an actual oil tank (C), which has undergone temporal changes of filling and emptying.

Each tank is thus made up of a rock funnel (A), concrete wall (B), and metal tank (C) in various combinations, as shown in Figure 5. Glass surfaces are then added to the existing frames, depending on their condition, and passageways, decks, and columns are inserted. Next, the various combinations of maintenance, erasure, addition, and modification can be noticed. 


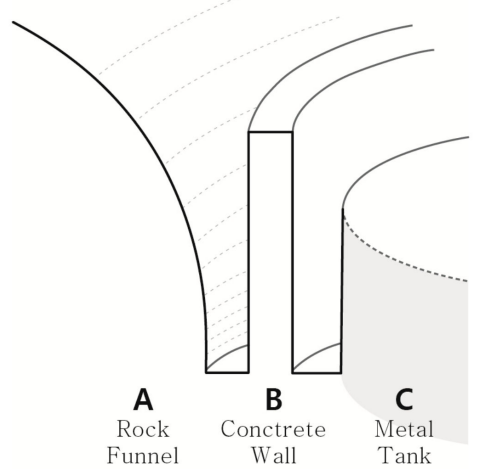

Figure 5. Combination of Structures, A (Rock Funnel), B (Concrete Wall) and C (Metal Tank) in the Mapo Oil Depot (Credit: Authors).

\subsection{Tank 1: $A+B+$ New Element}

Tank 1 is the smallest of the six tanks with an area of $554 \mathrm{~m}^{2}$, a diameter of $25 \mathrm{~m}$, and a height of $15 \mathrm{~m}$. It is fitted with walls and a roof made of glass in concrete areas left after dismantling the original tank. When entering the theater through the tunnel, the incision topography of the upper retaining walls is dramatic. In other words, in Tank 1, the natural hill (A), the lowered concrete wall (B) inside it, and the existing oil tank (C) have been completely dismantled and replaced with a new glass pavilion (Figure 6). Instead, the hills (A) and the concrete wall (B) have been transformed into the main attraction of the space's surroundings, as viewed through a glass screen.

Going through the tunnel towards the performance hall, the natural funnel-shaped topography emerges above the remaining concrete walls. The hall inside the tank has a wooden floor where 200 people can walk around without shoes. The space is flexible based on the audience size. Some people can dance or lay down on the floor. The architects proposed entering the hall through a tunnel with a sloped wall articulated by natural topography that gets higher and wider as it approaches the wall [5].

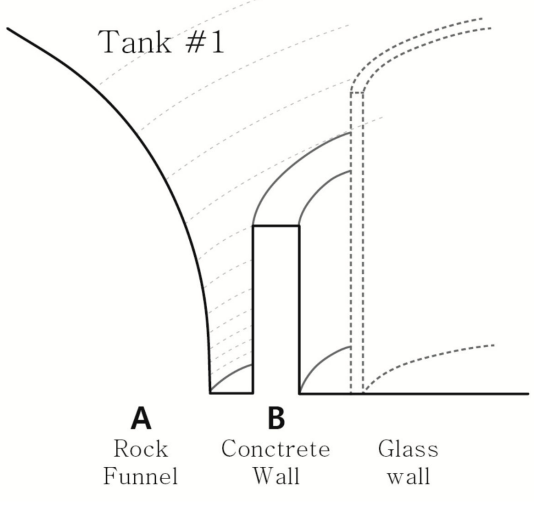

(a)

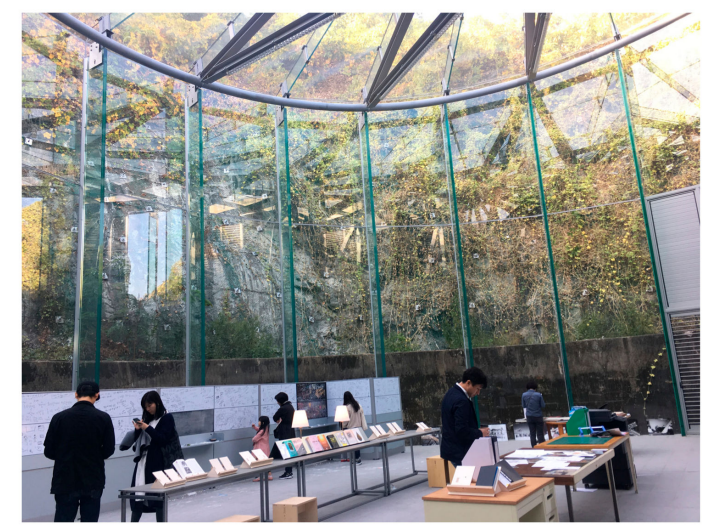

(b)

Figure 6. Features of Tank 1, (a) combination of elements, (b) inside the new built tank (Credit: Authors).

\subsection{Tank 2: $A+$ Lower $B$}

The original metal Tank 2 was completely removed from the location where it once stood, occupying an area of $2580 \mathrm{~m}^{2}$. The top of the tank, which runs naturally along the slope starting from the entrance, forms an outdoor stage. Stairs spread out to each side in a fan shape centering on the stage; they arranged in an orderly manner, although stones with different elevation are disordered. The concrete wall is now a major element of the stage. It is integrated with the floor while serving to distinguish external pathways from the performance space. The floor structure can accommodate diverse programs [14]. 
In Tank 2, the existing oil tank (C) was completely removed. The concrete protective wall (B) outside was partly demolished, and it was lowered so that the surrounding landscape (A) had a louder voice as a screen of a focal length, with the exception of the wall behind the stage which maintains its original height (Figure 7).

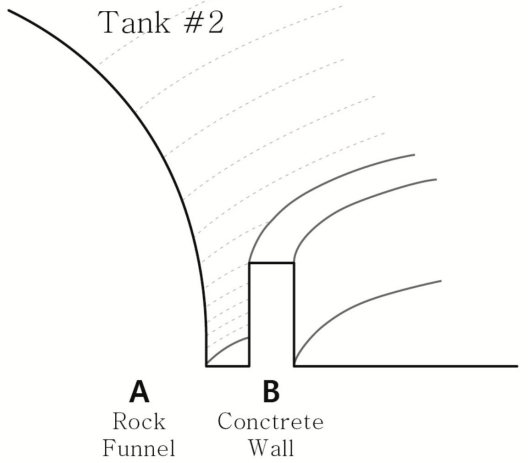

(a)

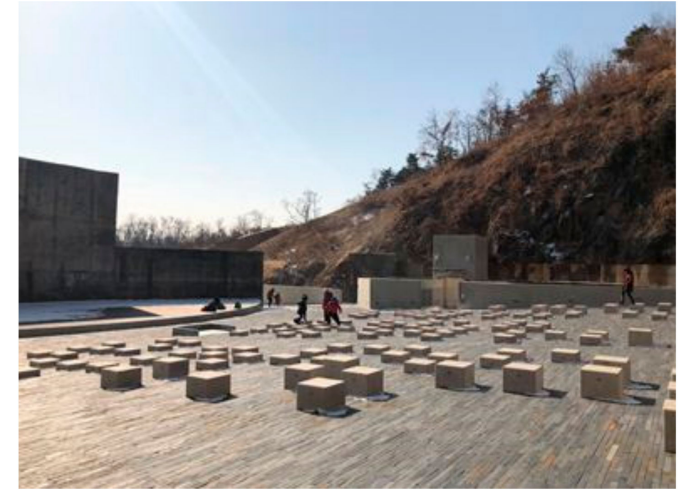

(b)

Figure 7. Features of Tank 2, (a) combination of elements, (b) outdoor stage (Credit: Authors).

\subsection{Tank 3: $A+B+C$}

Tank 3 was designated as a Future Heritage of Seoul site in 2013. It retained its original shape, allowing visitors to experience how deep the tank is buried into the ground. It covers an area of $1046 \mathrm{~m}^{2}$ with a diameter of $40 \mathrm{~m}$ and a height of $15 \mathrm{~m}$.

The tank was left in its preexisting condition, although the staircase was removed so no one can approach, making it an isolated island as Figure 8 below. However, everyone can recognize this area, and its presence emphasizes the renovations to the other tanks. This strategy serves to consolidate the other tanks and reconcile the artificial and natural in front of the concrete wall [14]. Such a use not only creates meaning, but also leaves room for future utilization.

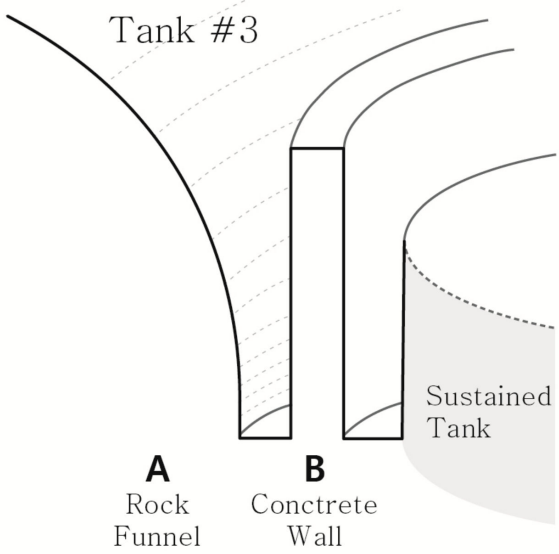

(a)

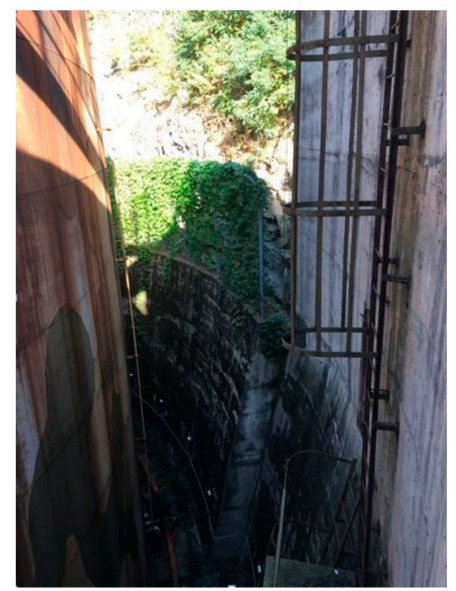

(b)

Figure 8. Features of Tank 3, (a) combination of elements, (b) original shape of the oil tank (Credit: Authors).

\subsection{Tank 4: $A+B+$ Passage Deck $+C+$ Columns}

Tank 4 maintains all the existing A, B, and C vertical structures described in the previous sections but makes dynamic changes to the layers between them. The tank has an area of $1228 \mathrm{~m}^{2}$ and maintains its original interior shape, which is used as special exhibition space. By inserting an artificial walkway between the metal tank (C) and concrete wall (B), the designers allow for a walking experience, and line of sight 
unattainable in previous structures as Figure 9 below. In such a manner, new space is created without modifying an existing structure by making columns wrap around existing ones yet remain separated [14].

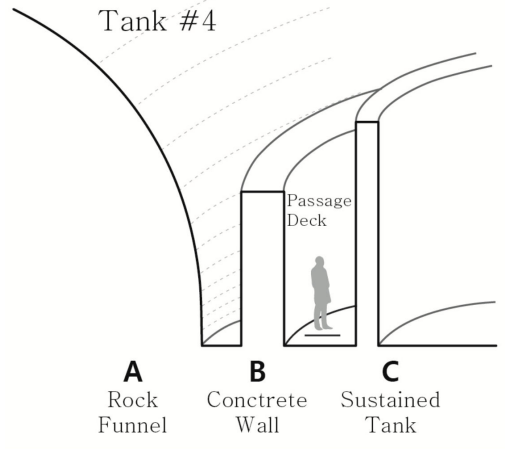

(a)

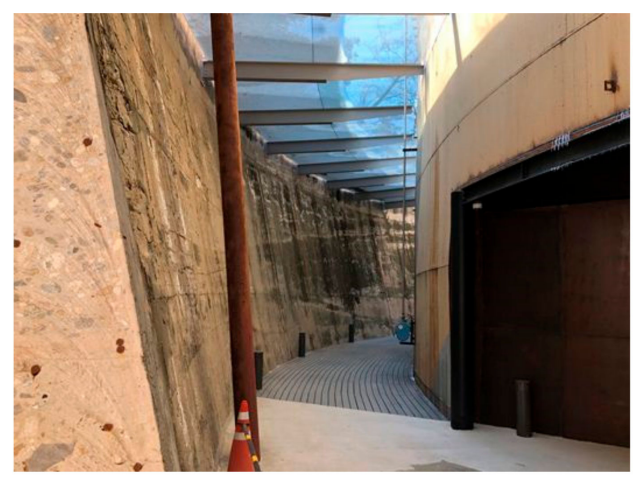

(b)

Figure 9. Features of Tank 4, (a) combination of elements, (b) internal space with glass walls and a roof (Credit: Authors).

\subsection{Tank 5: $A+$ Passage Deck $+B+C$ with Holes + Columns}

Both Tanks 4 and 5 involve a variety of penetrations and trenches in and out of the tank (C) and concrete wall (B), while maintaining the hill (A) and concrete protection wall (B) in their original states (Figure 10). This exposes the passage road and, by introducing a partial walkway and opening, differentiates the order of the existing elements.

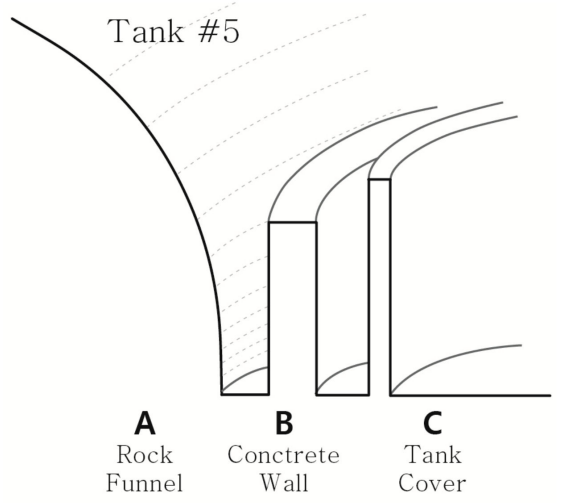

(a)

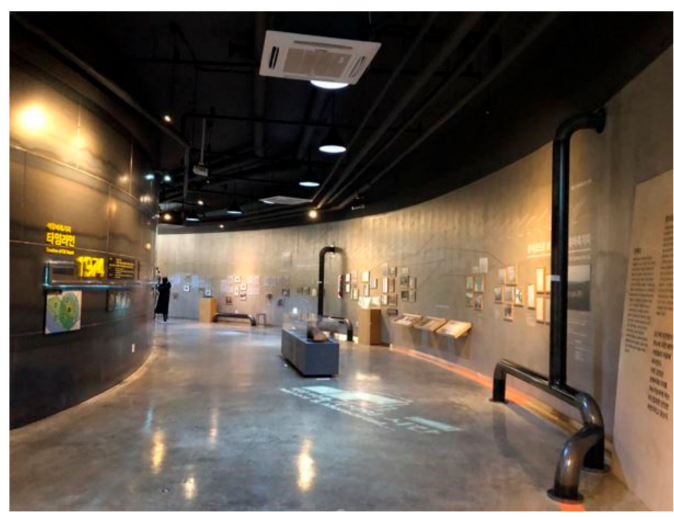

(b)

Figure 10. Features of Tank 5: (a) Combination of elements, (b) interior space of the tank (Credit: Authors).

The interior space of Tank 5 has become external space which works as a kind of a courtyard. There is suggested exhibition space at the second-floor level. In this context, the external structure becomes the wall for the internal space while the internal space becomes the external skin [13].

The second floor, meanwhile, becomes a unique exhibition space where visitors can see the inside and outside of the tank, the concrete retaining wall, the bedrock, and the cut-out area. It is organized so that visitors can see through the history of the oil deposit as they move around the space in a circle.

\subsection{Tank 6: New C}

Tank 6 is a completely new construction and the largest of the tanks with an area of $2948 \mathrm{~m}^{2}$, a diameter of $46 \mathrm{~m}$, and a height of $20 \mathrm{~m}$. Tanks 1 and 3 have been removed from their original locations and transferred to a more explicit area within the Depot [14]. The skin of the newly created tank stands completely free from the surrounding hills or interior pillars due its mix-matching of materials from existing tanks. It stands on a flat ground, exhibiting a distinctive presence and function in the complex. 
This tank is known as the Community Center (Figure 11) and can accommodate up to 300 people in a reading room, café, meeting room, and lecture hall. Anyone in Seoul is free to visit the space and access various materials related to the city's revitalization.

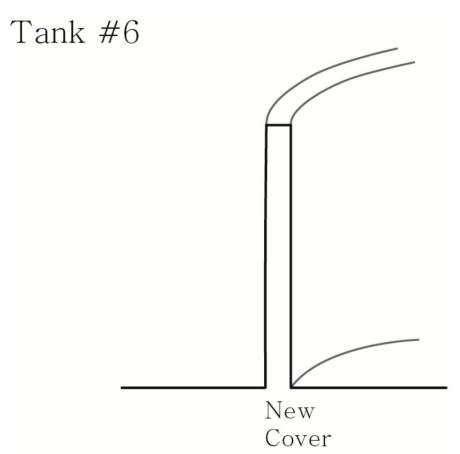

(a)

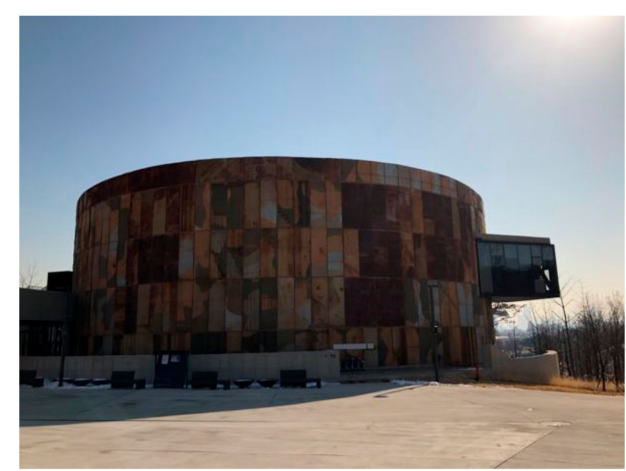

(b)

Figure 11. Features of Tank 6, (a) combination of elements, (b) entrance (Credit: Authors).

\section{Regeneration and Interaction with the Remnants}

The Mapo Cultural Oil Depot's regeneration strategy is to focus on natural surroundings and thereby address tectonic relations and reflect emotional realms. The Depot's renovations use sustainability to reflect the many incarnations of the land through a physical device, experience, and cognitive intervention. This section analyzes exactly how that is done in a viewpoint of respecting the values of authenticity and identity. It proceeds in following three stages. The various temporal messages (Section 4.2) that can be deduced from the remnants' relation to existing grounds (Section 4.1) and from the combination of remnants and new architectural constructions. And psychological phenomena through the interaction of memory and practice (Section 4.3). Through this, we can examine the values of authenticity of the depot from the perspective of remnant, which is an essential process to understand the collective design philosophy.

\subsection{Coordinating Natural Surroundings}

One of the most important things to consider about the new Depot is how it deals with the surrounding environment. The Depot is more meaningful when approached from the natural relationship between the site and the surrounding landscape. This space was forgotten to many people for years: Its location, on Mt. Maebong, makes it difficult to access and as an oil depot access by the public was forbidden. Therefore, entrants should make proposals considering connection from the outside of the site to make it an open park. The main entrance should be placed at the temporary parking lot next to the site and designed to naturally invite people into the park. The entire park must consider how people move among the buildings [3], making ground one of the most important physical resources.

The winning proposal, "Reading the Story of the Site," understood that the project's key goal is to restore access to this land and took the landscape into account in the overall design. The architects acknowledged the rough condition of the planned area. The rock bed explained the area's geography while trees were used to create a pathway, recreating walkways using already existing ginkgo trees. They also integrated existing drains with new ones; the five existing tanks already had independent waterways. Water stems from certain points for Tanks 1 and 2, while Tanks 3, 4, and 5 are linked to waterways at the entrance [14].

Based on these principles, the architects divided the grounds into three zones. The first was the upper zone tank area, where the rock bed explained the geographical condition of the planned area. The second level was the funnel-shaped tank area. The last level was the entry area, or the lower zone, where the main entrance was located. The designers planned to create an ecological area by 
reciprocating manmade structures with the landscape so that people could observe the gathering and drying of rainwater [14].

Therefore, a physical approach to designing the locations of the tanks considered balance with the existing landscape. In other words, determining heritage value should be done by zoning the site appropriately while maintaining existing natural surroundings.

\subsection{Tectonic Relation in Time Spectrum}

While the previous section addressed how the designers handled the land, this section addresses the more architectural aspects of the new Depot. Figure 12 shows how each of the six tanks can be situated in time. In other words, the combination of various elements in each tank outlined in Section 3 can also be understood as a non-visible phenomenon, or the accumulation of time. The size, spacing, and texture of each tank and the surroundings all indicate different eras in the site's history. The natural appearance of Mt. Maebong before the oil depot was established is the earliest time period represented, followed by construction and full-scale excavation in the 1970s. The period from 1976 to 2000, a time of solid and massive structures, is revealed by traces throughout the reservoir bases. Other aspects of the tanks, including the addition of cut surfaces and selective openings in the concrete walls, show the beginning of the revitalization process in 2014, after the tanks were emptied and the oil transferred. Finally, the completely new structures represent the present transformation of the site into a cultural base in 2017. Together, these aspects convey a strong heterogeneous message about the site's identity and time period.

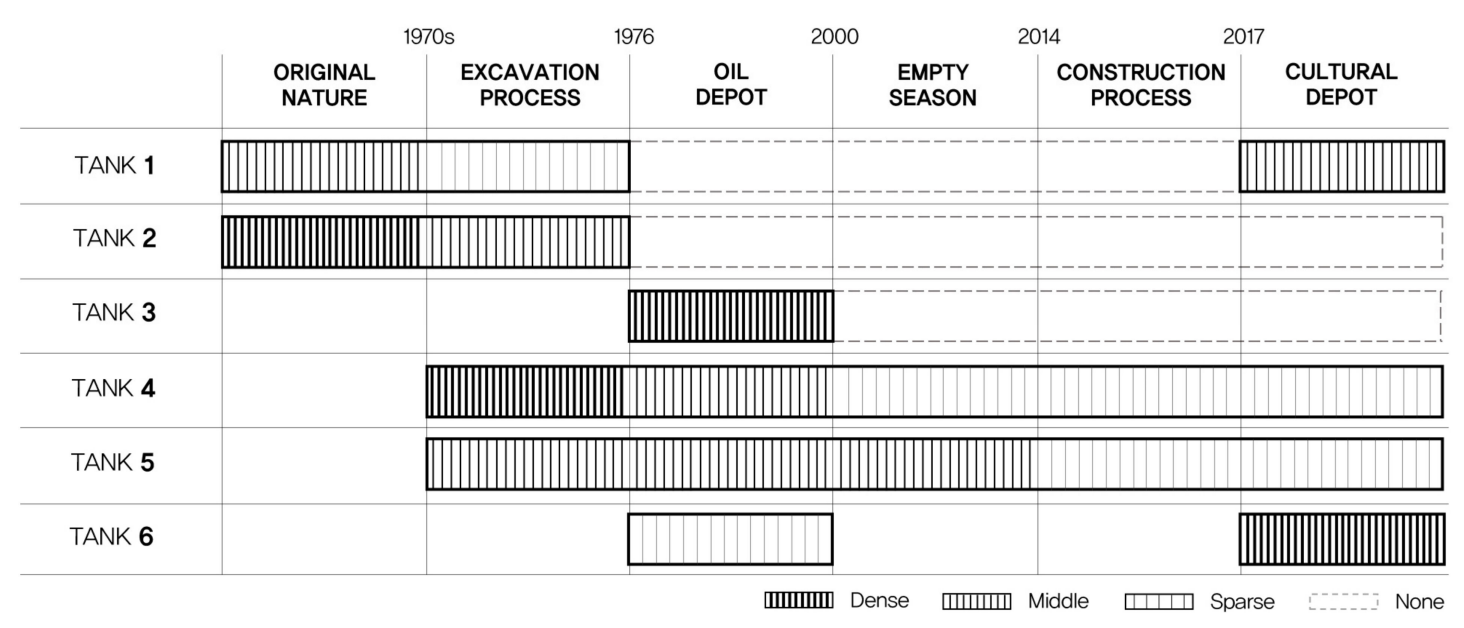

Figure 12. The historical eras recalled by each tank in the Mapo Oil Depot (Credit: Authors).

The different time periods are revealed in different ways through the site and in different tanks. Tanks 1 and 2, for example, both draw attention to the pre-1970s original nature of the site. However, these two tanks differ drastically in other ways. Tank 1 simultaneously illustrates the oldest and newest times periods while Tank 2 juxtaposes the two oldest eras in the site's history. Tank 3, meanwhile, is the only one that preserves the unique state of the solid oil tank between 1976 and 2000. It sits in one corner of the site emphasizing the specificity of the surrounding tanks. The entrance of Tank 4 exposes the cut concrete surfaces the most dramatically, revealing traces of the excavation process.

In other words, each tank reflects different aspects of the space's personality and characteristics (Figure 12) by visually revealing and stimulating the memory of specific time periods in the site's history. At the same time, contrast and juxtaposition are also used to suggest different time periods. In Tanks 1 and 2, both of which illustrate two very different time periods, the contrast between the two is evident. On the other hand, in Tanks 4 and 5, which represent continuous time periods, the viewer comes to understand that space flows through the in-between space and the artificial deck to become more dramatic. In this way, the design strategy shows how various methodologies can be used to help users experience both traces of the old and the functionality of the new with a unique frequency and intensity. 


\subsection{Reflecting Emotional Remnants}

As mentioned above, if the tectonic relation is focused on the Oil Depot's physical aspects, the heritage value is revealed through memories and emotional remnants. This is also done through the modern utilization of old structures: The architect's new way of thinking leads to a sense of newly created space.

Tank 1 is a clear example of this contrasting effect. There was an effort to aggressively update the tank by replacing metal, the tank's main material, with glass pavilions of the same size. While the existing metal tanks allowed only a dark gaze toward the interior, the glass pavilion allows a full visual of the exterior surrounding areas. The glass's transparency highlights the concrete wall beyond, the natural hillsides above, and the vine surrounding the structure, making visible a clear contrast between the new and the old structures. Users become more aware of the passage of time through this visual contrast and can simultaneously recognize the novelty of the new and the inherent charm of the old.

Tank 2 attempts to do this in a different way, through active intervention. The strong concentric structure of the existing oil depot breaks the traditional relationship between the oil tank, the concrete wall, and the natural hill. Tank 2 was emptied, but not replaced with new material. The concrete wall surrounding the tank, meanwhile, was lowered, creating an empty space surrounded by the outer natural hills. This, together with the raw feel of the exterior, creates a sense of nothingness that cannot be felt through merely the rigid concentric structure. Instead, the exposure to the surrounding hills leads to immediate assimilation of the tank's interior and exterior. This is a dramatic production of categories that cannot be reached by existing relationships.

Tanks 4 and 5 attempt to add additional circulation and lines of sight to the existing concentric structures. In Tank 4, a circular deck is inserted between the oil tank and concrete wall, creating a previously unconnected line and new spatial relationship. This allows users to touch, look, and walk through the tanks and walls in close proximity. Likewise, Tank 5 produces a new gaze through the insertion of a new shell and addition of openings. Paradoxically, this too conveys the passage of time. Eventually, the principle of reversal in Tanks 4 and 5 is the same.

People's perceptions of a place come from their memories and previous experiences. These are invaluable in creating a place's spiritual heritage: "Place dominates memory, memory dominates consciousness." The depot, a previously abandoned facility slipping away from peoples' memories, is today a revitalized site that both preserves history and also allows people who lived through its various eras to share their memories, thereby renewing the site's meaning. This has been reflected in the Depot's oral records and archives.

To some the facility was a secure area with limited access, while to workers there it was a place of daily routines. However, from the perspective of internal workers, it was a place of daily routines. These people often recall the danger and sense of fear that accompanied working here. For example, Mr. Chang, a branch manager at the oil depot from 1987 1983, said:

"It's not one, but five tanks. It's not that one person has to go to all of them, but honestly, it is a little hard having to climb down a ladder. I mean, in the winter when it snows the foot pads are very slippery. It isn't as though one can heat it and defrost it either. Anyway, it's slippery. If any accident would happen, it would be a big one. Think of if one would fall to a concrete floor. In front of main facilities, there are keys hanging called patrol keys. So the front gate employee patrols the premises with a watch. All alone at night. And it's all raining. If you have been inside of a tank, you should know that it is creepy. In places like that, the keys are on the inside, so you have to go even if you don't want to. It was very scary to go alone. You are supposed to hang it on the entrance to see if there is any sign of damage or entry. It takes about an hour if you patrol alone. Because you have to check everywhere. So when doing so, you feel yourself cold sweating due to fear." 
Other previous workers recall a feeling of pride, attending events like family picnics, and intimate relations between staff members. The vice president from 1981 to 1983 said:

"If anything is rewarding, it would simply be the pride of supplying oil in case the capital area was ever in peril. We are responsible for keeping citizens of Seoul from having to worry by reserving a sufficient supply of energy. There aren't many employees here. So everyone is like family. A lot of the work was manual labor. If there was ever a faulty fire hydrant, we would take shovels and pickaxes to fix it, so yeah, there was a lot of manual labor. It was because there was no automated system and everything was manual, like in the army. That's why there was such a bond between employees. If anyone was in a hard situation, everyone would gather up to help. If anyone took a day off, we would ask why they took the day off. But these days, even though there are many workers, if someone takes a day off, nobody would question it, that's the difference."

Today, both newcomers and previous workers with differing views toward the site are able to share in their own meanings of the site. While the $15 \mathrm{~m}$ tall tank could be considered a place from which one could have a fatal drop and Tank 1 could be remembered as a frightening space where people had to be careful to avoid static electricity, it is also a community gathering place. All of this history goes into making the Depot an important heritage site today.

\section{Results for Case Contribution}

\subsection{Evaluation from the Proposition and the Reality}

The most representative part of the successful design strategy of the Mapo cultural depot is that the distinctive design characteristics of a total of six tanks are well utilized in actual usage patterns. As analyzed in Section 4, the six tanks retained the existing structures of A, B, and C in a unique way. Since its opening, each tank has led to the participation and experience of the citizens in various ways in accordance with the individual character of this structure. This is because it maximizes the spatial attraction of the architectural Remnant by realistically appealing the heritage value. A large concert wall (element B) was used as the background for the concert (Figure 13a). Also, a night circus event (Figure 13b) utilizing the dark atmosphere inside the metal tank (element C) has been carried out. In addition, Tank 1 , which has an open and intimate atmosphere, conducts small-scale citizen participation programs in the background of rock funnel (element A) and concrete wall (element B). This distinctive design strategy of architectural heritage is used as a direct link between citizen participation and utilization. Moreover, the utilization aspect of energy resources, which was the initial stage of the depot, has been continuously implemented since the actual opening. As part of the recycled resources mentioned in Section 2.1, we continue to recycle water within the cultural depot, which in conjunction with the play program (Figure 13d) contributes to the harmonious use of the environment and heritage.

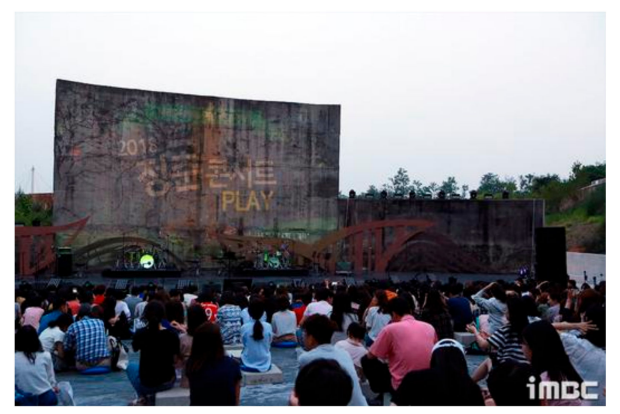

(a)

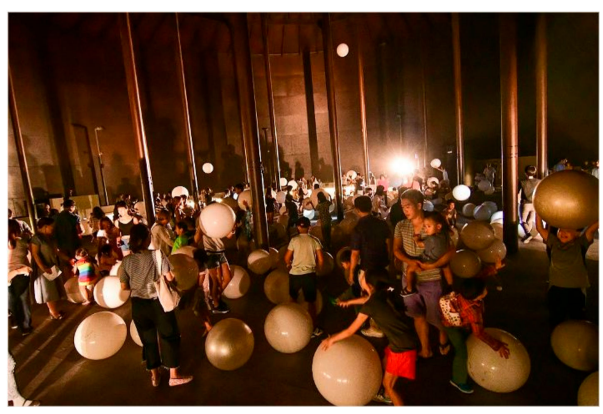

(b)

Figure 13. Cont. 


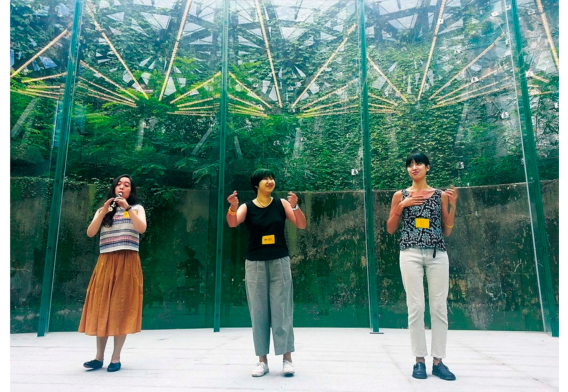

(c)

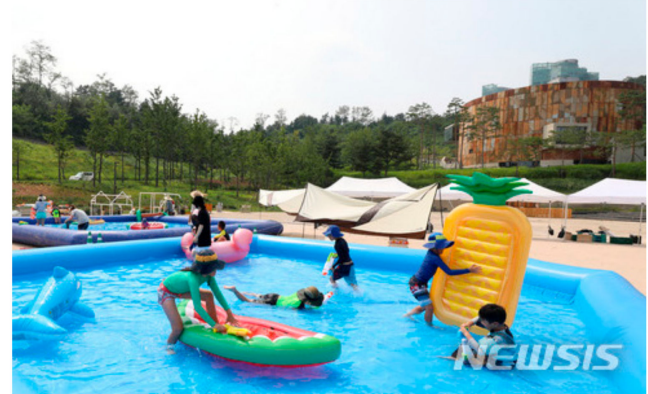

(d)

Figure 13. Participation and Experience of Seoul Citizens, (a) Youth Concert at tank 2 [15], (b) Night Circus at tank 4 [16], (c) Body percussion at tank 1 [17], (d) Event of "Aloha Mapo Depot" [18].

On the other hand, there were differences from the initial intention. For example, the last tank, T6, was located at the very beginning of the site and was read as the most visible landmark for the visitors. As mentioned in Section 3.6, T6 is the only new building unlike other tanks and acts as an auxiliary facility to assist the main functions of other tanks. Recognition as a central building for those visiting the depot contravenes the authenticity of the "value of memory" that was highlighted in Section 4.3, despite the tank with the lowest heritage value in terms of formation and function. This is also pointed out in the following column.

Any new construction conflicts with the philosophy of regeneration. Respecting the historical nature of the place and finding the seeds of new life there is the point of play. A similar case, commonly referred to as the City of Gasometer in Vienna, has also helped to maintain the old form of industrial facilities in the process of reclaiming four gas reservoirs as apartment houses for young people. The three buildings were so rebuilt, and adding a new building to one vault is a cue for space dynamics. In other words, they did not build a new building in the wrong place.

The position and size of $\mathrm{T} 6$ are also not appropriate. It is positioned in the center without regards to the flow of the existing tanks. As a result, T6 is mistaken as one of the old oil tanks if you pass by the road or look at the nearby sky park. The scale is overwhelming enough to make the existing facility shabby. That's why you should not put a new building in revitalization project. If you need an office or rest area, it should be built modestly in a different location [19].

The value of the heritage is derived from the authenticity of the preserved heritage. T6 of the Mapo cultural depot was not built in a way that matched the origin of the tank. In addition, since the depot is designed around existing tanks, it is also a pity that lack of connection between various external spaces other than tank sites was left out. Linkage work across the outer space between the tank and the tank could have created a flexible solution to cope with various changes in weather. It is true that the current base has a large usage deviation of the outer space depending on the season. It is necessary to consider various outdoor spaces depending on the season.

\subsection{Contribution from Analysis}

Through the Mapo project, we can see that when people enjoy culture and entertainment in a place with a heritage, the place can become a place of learning more than entertainment. Places can grasp the natural environment, and inherit the historical value surrounding the building itself, by finding the value of the place through the heritage and by delicately controlling the density. The keyword here is a control of density. In other words, it is more important to leave a void than to place something. Especially for industrial heritage, it is an important point to consider what to leave and erase. This case was contributed to urban sustainability in that it presented an architectural design that implements respectful regeneration.

The general contribution from this case for the industrial heritage is as follows. The first requirement is the control of the density. This means that the density should be delicately controlled between the void 
and the solid. Buffering makes it possible to maintain the value of the heritage while at the same time maximizing the utilization. This is closely linked to the second element-flexibility. Heritage is not fixed, but changes in trace of time. Therefore, the space that shows the heritage or the program containing it should be flexible and adaptable to the situation. The third requirement is sense of place. It's not just entertainment, so you have to make sure that you have the authenticity of your memory. These following design strategies can be applied in other similar cases to pursue industrial heritage.

\section{Conclusions}

Focusing on the heritage value and the issue of sustainability, this study analyzed the design strategy of the Mapo Cultural Oil Depot in Seoul. It argues that the best way to experience a site's heritage is to both preserve the site while creating a complex experience through design. In such a way, the Depot both embraces the industrial heritage of Seoul before the 1970 and tells the current story of the site's six separate tanks, interweaving these historical narratives through traces of the original buildings and new construction. Such creative design plays a major role in the ongoing successful experience of this heritage.

A literature review of heritage values in Chapter 2 reveals the unique history and identity of the Mapo Cultural Depot. Chapter 3 then identifies individual design strategies as architectural heritage for each tank. The criteria for classification were set as the outermost rock funnel (A), the concrete wall (B) as a protective device, and the metal tank (C) as a container (Figure 5). Section 4, as a discussion section, analyzed and criticized the overall design strategy and philosophy by allowing various variations and combinations on the set standards. The results of the analysis are as follows.

Firstly, on the issue of coordinating natural surroundings, an initial approach to designing the zoning of the locations considered balance according to the line of existing landscape. In other words, heritage value should be determined by categorizing the site appropriately while maintaining existing ground form.

Secondly, the spatial structure of tank reflects each aspect of the tanks' identity and characteristics by reminding and stimulating the memory of relevant time periods in the site's history. At the same time, contrast and juxtaposition are also used to suggest different time zones. In this way, the design strategy shows how various methodologies can be used to help users experience both traces of the old and the functionality of the new with a unique frequency and intensity.

Thirdly, heritage values are strengthened through emotional remnants and memory. Depending on the materiality and bonding style of the newly added building, various senses and memories are stimulated, thereby maximizing the inherent value and existence of the old structures. In this study, we analyze the psychological process according to the situation by dividing the situation into the case where the memory is consistent with the existing custom and the case where it is not.

The evaluation of the Mapo Cultural Depot is based on the following. The differentiated design strategy for each tank distributed throughout the base is considered to be a very positive strategy because it leads to diversification of practical use. In addition, the utilization of energy resources, which was set in the early stage, is being practiced continuously. Especially, it is actively continuing in terms of harmony of nature and experience through connection with play programs provided to users. However, the current position and scale of $\mathrm{T} 6$, in terms of pursuing the value of the remaining elements and the memory of the time inherent in each tank, is detracting from the authenticity of the heritage. In addition, seasonal application of the exterior space around the tanks should be reconsidered.

This study suggests that the abstract concept of urban sustainability has become a growing priority for multiple stakeholders. Such a priority will not only enrich citizens' urban experience, but ultimately play a role in raising cities' heritage value from an environmental, social, and economic perspective. The Depot stands as a prime example of how to accomplish this, since it embraces both the architectural and emotional legacies of the site. It both sits in harmony with the landscape and allows people to experience and communicate their feelings of the site through the distributed routes, thereby allowing people to share in a sense of materiality and memory. 
Author Contributions: All of the authors contributed equally to this work. All authors have read and approved the final manuscript.

Funding: This research was supported by a Basic Science Research Program through the National Research Foundation of Korea (NRF) funded by the Ministry of Science, ICT and future Planning (NRF-2016R1C1B1013955).

Conflicts of Interest: The authors declare no conflict of interest.

\section{References and Notes}

1. James, P. Urban Sustainability in Theory and Practice: Circles of Sustainability, 1st ed; Routledge Books: Oxford, UK, 2014; pp. 22-24.

2. Han, A.; Kwak, D. A Sustainable Urban Regeneration Design as a Creative Way to Utilize the Industrial Heritage. Available online: http:/ / www.riss.kr.openlink.ssu.ac.kr:8080/search/detail/DetailView.do?p_mat_ type=1a0202e37d52c72d\&control_no=9519aea540f00d7e7ecd42904f0c5d65 (accessed on 9 September 2018).

3. Seoul Metropolitan Government. International Competition for Rehabilitating Mapo Oil Depot into a Cultural Depot Park. Available online: http:/ / competitions.archi/competition/international-competition-for-rehabilitating-mapooil-depot-into-a-cultural-depot-park/ (accessed on 9 September 2018).

4. Metzger, J.; Olsson, A.R. Sustainable Stockholm: Exploring Urban Sustainability in Europe's Greenest City; Routledge Books: Oxford, UK, 2013; pp. 71-101.

5. Boone, C.G.; Fragkias, M. (Eds.) Urbanization and Sustainability: Linking Urban Ecology, Environmental Justice and Global Environmental Change; Springer: Dordrecht, The Netherlands, 2012; pp. 18-20.

6. Manzi, T.; Lucas, K.; Jones, T.L. Social Sustainability in Urban Areas: Communities, Connectivity and the Urban Fabric; Routledge: Oxford, UK, 2010; pp. 105-159.

7. Back, S.A. A Study on the Design Checklist for Ecologically Sustainable Public Space. Ph.D. Thesis, Hongik University, Seoul, Korea, February 2009.

8. Nadarajah, M.; Yamamoto, A.T. Urban Crisis: Culture and the Sustainability of Cities; UNN Press: Tokyo, Japan, 2006; pp. 1-79.

9. Kang, J. A Critical Study on Urban Regeneration and Public Opinion Formation. Available online: http:/ / kiss.kstudy.com/journal/journal-view.asp?key1=30352\&key2=3506 (accessed on 9 September 2018).

10. González, M. Peter Zumthor's Kolumba Museum Through the Lens of Rasmus Hjortshøj. Available online: https: / / www.archdaily.com/877432/peter-zumthors-kolumba-museum-through-the-lens-of-rasmus-hjortshoj (accessed on 10 September 2018).

11. Kang, M. KANGMS@ewha.ac.kr.

12. Kim, E. kimej94@naver.com.

13. Han, E.H. Excavate Abandoned Memory of Culture, Joongang Sunday. Available online: http://mnews. joins.com/article/21942505\#home (accessed on 1 April 2018).

14. Sebastian, J. International Competition for Rehabilitating Mapo Oil Depot into a Cultural Depot Park; Seoul Metropolitan Government: Seoul, Korea, 2015.

15. Lee, M.H. 'Youth Concert', Summer Night with Music and Youth. Available online: http://news.zum.com/ articles / 45961164 (accessed on 8 August 2018).

16. Yu, Y.S. First Circus Festival Opens. Available online: http://www.nocutnews.co.kr/news / 4967746 (accessed on 8 August 2018).

17. Kim, B.G. Citizen Participation-Oriented Planning Performance. Available online: http:/ /www.seouland. com/arti/society/society_general/2479.html (accessed on 8 August 2018).

18. Kim, S.W. 2018 Aloha Cultural Depot. Available online: http:/ / www.newsis.com/view/?id=NISI20180727_ 0014327300 (accessed on 8 August 2018).

19. Son, S.H. Why Is Mapo Cultural Oil Depot Uncomfortable? Available online: http:/ / m.kmib.co.kr/view. asp arcid $=0923828129 \&$ code $=11171362 \& c p=n v$ (accessed on 8 August 2018).

(c) 2018 by the authors. Licensee MDPI, Basel, Switzerland. This article is an open access article distributed under the terms and conditions of the Creative Commons Attribution (CC BY) license (http://creativecommons.org/licenses/by/4.0/). 